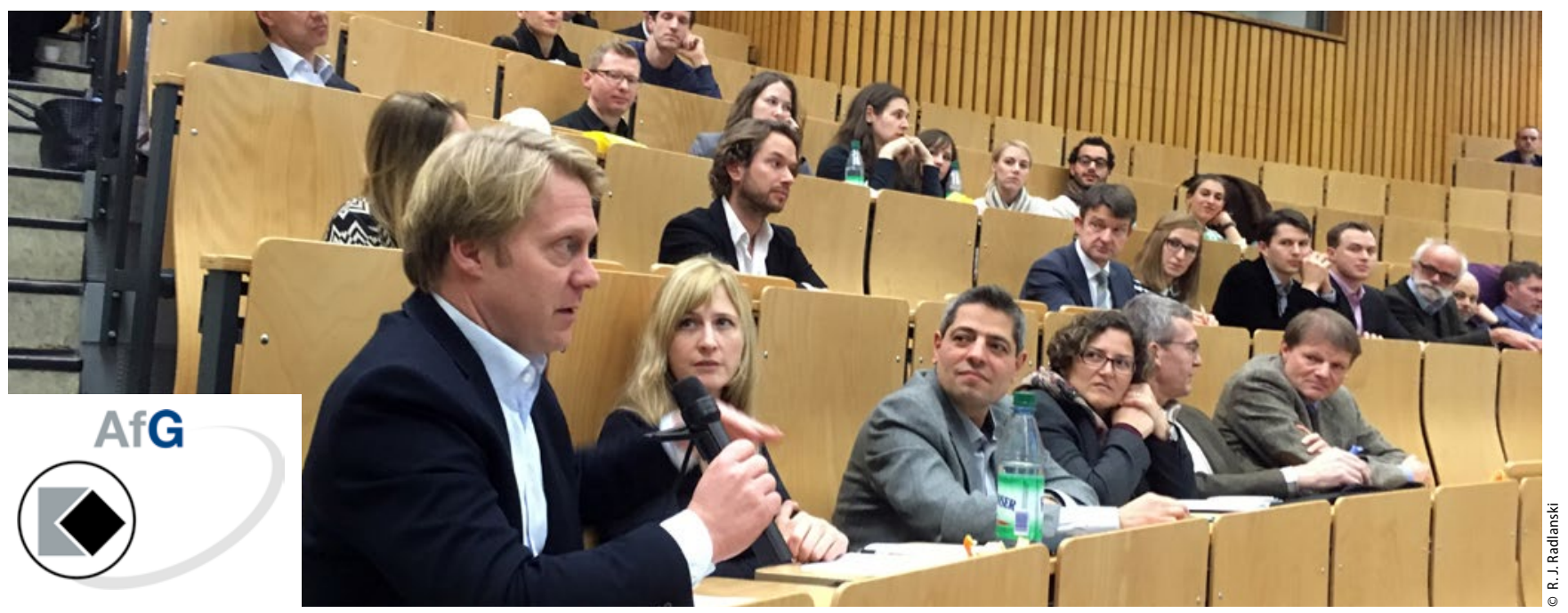

\title{
Die Arbeitsgemeinschaft für Grundlagenforschung stellt sich vor
}

Die Arbeitsgemeinschaft für Grundlagenforschung (AfG) trägt die Idee der Gründungsväter weiter, die ein Forum für den freimütigen Gedankenaustausch aller Wissenschaftler geschaffen haben, das für jeden Teilnehmer einen wirklichen Gewinn für eigene Forschungsvorhaben darstellt, überregionale und fachübergreifende Kooperationen fördert und Kenntnisse für den Unterricht für Dozenten und Studenten ermöglicht - so stand es im Bericht über die erste Jahrestagung 1968.

A uf den AfG-Jahrestagungen stehen die Forschungsinhalte aus allen Grundlagenbereichen der Zahn-, Mund- und Kieferheilkunde im Vordergrund. Die Diskussionen dienen dem tiefen Verständnis und regen den fachübergreifenden Austausch an. Nicht selten entstehen gerade so und ungeplant neue Ideen, Fragestellungen und ungewöhnliche Kooperationen. Es gibt Preise für Nachwuchswissenschaftler, wobei die Preisträger ihren Vortrag am jeweils nachfolgenden Termin des Deutschen Zahnärztetages vorstellen. In der ungezwungenen Atmosphäre fühlen sich Newcomer schnell wohl und fassen Vertrauen in die eigene Arbeit. Und wer möchte, kann sogar 14 Fortbildungspunkte einreichen.

\section{Mitgliederzahl:}

ca. 250

\section{Gegründet:}

1968

\section{Präsident:}

1. Vorsitzender: Prof. Dr. Dr. R. J. Radlanski

2. Vorsitzender: PD Dr. M. Wolf

Schriftführer: Dr. A. Voigt

\section{Jahrestagung:}

Die Jahrestagung findet meistens am 2. Januar-Wochenende in der Universitätszahnklinik Mainz statt.

\section{Preise/Auszeichnungen:}

$\rightarrow$ Preise für den besten (und zweitbesten) Vortrag (Nachwuchswissenschaftler)

$\rightarrow$ Preise für das beste (und zweitbeste) Poster (Nachwuchswissenschaftler)

Die Preisträger erhalten ein Preisgeld (Firmensponsoring) und halten einen Vortrag über ihr Thema auf dem Deutschen Zahnärztetag im Rahmen der Gemeinschaftsveranstaltung zwischen AfG und TAGRegMed (Transdisziplinärer Arbeitskreis Regenerative Medizin).

\section{Weiterbildungsmöglichkeiten:}

Die AfG bietet formal keine Weiterbildungsmöglichkeiten an. Die Vorträge anderer Teilnehmer und die Diskussionen tragen aber zur persönlichen Weiterbildung bei.

\section{Infos zur Mitgliedschaft}

Grundvoraussetzung ist eine Mitgliedschaft in der DGZMK (diese ist beitragspflichtig). Die Mitgliedschaft in der AfG kann dann auf Antrag erfolgen und ist kostenfrei. Hierfür wichtig ist das Interesse am wissenschaftlichen Arbeiten. Eine aktive Beteiligung in der AfG, Besuch der Jahrestagungen und wissenschaftliche Beiträge sind erwünscht. 